Article

\title{
Effect of Acetone Content on the Preparation Period and Curing/Pyrolysis Behavior of Liquid Polycarbosilane
}

\author{
Yizhi Liu ${ }^{1, * \mathbb{C}}, \mathrm{Xu} \mathrm{Liu}^{1}$ and Ping $\mathrm{Hu}^{2, *}$ \\ 1 Department of Astronautic Science and Mechanics, Harbin Institute of Technology, Harbin 150001, China; \\ 1171800111@stu.hit.edu.cn \\ 2 National Key Laboratory of Science and Technology on Advanced Composites in Special Environments, \\ Harbin Institute of Technology, Harbin 150001, China \\ * Correspondence: liuyizhi@hit.edu.cn (Y.L.); huping@alu.hit.edu.cn (P.H.)
}

Received: 14 September 2020; Accepted: 26 October 2020; Published: 28 October 2020

\begin{abstract}
A novel approach was proposed to increase the compactness, shorten the preparation period, and reduce the preparation cost by introducing acetone to optimize the polycarbosilane impregnation process. The porosity in internally derived $\mathrm{SiC}$ ceramics decreased and pore size was limited by using this new method, which led to higher compactness. Meanwhile, with the increase in acetone content, the viscosities of polycarbosilane and the wetting angles of polycarbosilane/graphite decreased appreciably, and the viscosity was $6.0 \mathrm{mPa} \cdot \mathrm{s}$ with $40 \mathrm{wt} . \%$ acetone added-a factor of about 30 lower than that of original polycarbosilane. The wetting angle between polycarbosilane and graphite significantly decreased by $40 \%$, which resulted in an enhancement in the impregnation efficiency of liquid polycarbosilane and a much shorter preparation period. This work provides a convenient and efficient method that is assistant during the practical production process of carbon fiber reinforced ceramic matrix composites (CMCs).
\end{abstract}

Keywords: polycarbosilane; acetone; viscosity; wettability; impregnation efficiency

\section{Introduction}

Carbon-fiber-reinforced ceramic matrix composites (CMCs) are advanced materials, which not only possess those outstanding properties of conventional $\mathrm{C} / \mathrm{C}$ materials but also perform with the advantages of high specific strength, high specific modulus, and superb mechanical properties at room and high temperature, as well as excellent oxidation ablative performance [1]. Hence, such excellent materials have attracted the attention of many scholars worldwide. Furthermore, they are applied to numerous aspects, in both military and civilian use, such as sliding components, engines, cutters, brakes, etc. Such materials are also believed to raise the efficiency of turbines and cut emissions at the same time [2-4]. In addition, considering their specific properties, they are mainly expected to be the important and irreplaceable candidates for high-temperature structural components, such as nose cones and wing leading edges of hypersonic aircraft [5-9]. Generally, CMCs are composed of carbon fibers and ceramic matrix. Among these, the carbon fibers serve as strong skeletons, and the ceramic matrix serves as a supporter to connect the whole structure. It is necessary to introduce ceramic phase into carbon fiber braid in practical production; therefore, the quality of CMCs will largely depend on the properties of the ceramic matrix and the mobility of ceramic precursors. Among CMCs, $\mathrm{C} / \mathrm{SiC}$ composites or ultra-high-temperature ceramic (UHTC)-modified C/SiC composites are the most important materials in the engineering application [10-13], and the composites are usually fabricated by the precursor infiltration and pyrolysis (PIP) process using polycarbosilane precursors as raw materials [14-16]. 
Originally, polycarbosilane is mostly solid and should be dissolved by organic solvents. However, the wettability between a polycarbosilane-organic system and carbon fibers is poor, which results in the low impregnation efficiency and a long preparation period. Even worse, the high content of organic solvents may lead to a relatively low volume ratio of polycarbosilane, which means a relatively high economic cost. The polycarbosilane we use today is liquid, and compared to the previous solid polycarbosilane-organic solvents solution, its liquidity has improved a lot. Nevertheless, this liquid phase has a high viscosity, leaving the impregnation effect unsatisfactory. Therefore, reducing the viscosity of polycarbosilane (PCS) effectively and improving the wettability between carbon fibers and ceramics at the same time is of great interest. Over many years, researchers have developed a variety of methods to solve the problem of low impregnation efficiency during the PIP process and typically introduce xylene or DVB solutions $[17,18]$. However, those solvents are poisonous and detrimental to environmental protection [19]. Moreover, the PCS/xylene system is prone to "foaming" at high temperature, resulting in a decline in infiltration efficiency [20]. Researchers also found that increasing the temperature of the polycarbosilane precursor could decrease its viscosity within a certain range. However, when the temperature was high $\left(>80^{\circ} \mathrm{C}\right.$ or more), it can easily lead to the rapid curing and failure of the polycarbosilane precursors, and the viscosities of the precursors will increase sharply in the several hours after heating, which extensively hinders the impregnation process [21-23]. Hence, exploring a reasonable method to effectively reduce the viscosities of precursors and greatly improve the wettability between carbon fibers and PCS that can lower the cost in time and money and can optimize impregnation process is presented as imminent and imperative work.

In this work, an innovative method of adding acetone to reduce the viscosity of liquid polycarbosilane (L-PCS) and improve the wettability between L-PCS and carbon fibers was carried out. To investigate the effect of acetone addition on L-PCS, the evolution behaviors of bond energies, components, and microstructures during PCS impregnation-curing-pyrolysis processes were analyzed by using scanning electron microscope (SEM), X-ray diffraction (XRD), Fourier transform infrared spectroscopy (FT-IR), and Raman. What is more, the influences of acetone content on compactness, viscosities of polycarbosilane precursors, and the wettability between PCS/graphite were also investigated.

\section{Experimental Procedures}

\subsection{Raw Materials}

The liquid polycarbosilane precursors (L-PCS, whose molecular chain consists mainly of carbon and silicon atoms with the rest comprised of hydrogen atoms) were provided from the National University of Defense Technology (Changsha, China) and the number average molecular weight and weight average molecular weight of L-PCS were 1800 and 3500, respectively [24,25]. Both acetone solvent $(99.6 \%$ ) and Karstedt's Catalyst (which contributes to the curing process) were obtained from Shanghai Aladdin Chemical Reagent Co., LTD (Shanghai, China).

\subsection{Materials Preparation}

A well-mixed mixture of $1.5 \mathrm{~g}$ curing agent and $150 \mathrm{~g}$ L-PCS was successfully produced after stirring for 10 min using a magnetic stirrer (PC-210, Corning Inc., Corning, NY, USA). Then, the mixture was divided into seven parts of equal weight. Among them, one sample was with $0 \mathrm{wt} . \%$ acetone as a reference sample, and the acetone content for the other six samples were $1 \mathrm{wt} . \%, 2 \mathrm{wt} . \%, 5 \mathrm{wt} . \%, 10 \mathrm{wt} . \%$, $30 \mathrm{wt} . \%$, and $40 \mathrm{wt} . \%$, respectively, based on the weight of L-PCS. The divided L-PCS samples, labeled as L-PCS-0, L-PCS-1, L-PCS-2, L-PCS-5, L-PCS-10, L-PCS-30, and L-PCS-40, were set at room temperature for several hours until no weight loss was detected. The weight of the original L-PCS was taken and recorded as well as when the weight of the solution was close to the original; the mass was measured at all times. Then the above samples were cured at $200{ }^{\circ} \mathrm{C}$ for $2 \mathrm{~h}$. Finally, the pyrolyzed samples prepared with different acetone ratio were obtained after pyrolyzing for $1 \mathrm{~h}$ in tube furnace at $1300^{\circ} \mathrm{C}$ 
under flowing argon protection atmosphere. The size of all the samples was $15 \mathrm{~mm} \times 15 \mathrm{~mm} \times 10 \mathrm{~mm}$. The surfaces of all samples after curing and pyrolyzing were not further processed in order to conduct scanning electron microscopy (SEM) observations. After that, every sample was broken into two pieces to obtain their SEM tests on fracture surfaces. The Au coating was achieved by low vacuum sputter coating of the sample for $120 \mathrm{~s}$. Additionally, carbon fibers were not used in this paper.

\subsection{Characterization}

The wetting angles between L-PCS solutions and a standard graphite sample were tested by wetting angle measuring instrument (VAF-30, Beijing Huahai Zhongyi Industrial Furnace Co. LTD, Beijing, China). The viscosities of L-PCS precursors at room temperature were analyzed by a rotating viscometer (DV-II+Pro, Brookfield Ltd., Brookfield, USA). X-ray diffraction (XRD, X'Pert Pro MPD, Almelo, Holland) was used to identify the crystalline phase of cured and pyrolyzed samples. The Raman spectra were measured in a Renishaw spectrometer by irradiation with a $532 \mathrm{~nm}$ laser, and the bonding energy of samples were determined by Nicolet is50 infrared spectrometer (FT-IR, Nicolet is5003190721, New York, USA). The surface and fracture morphologies combined with element mapping of each sample were obtained by a HELIOS Nanolab 600i scanning electron microscope (SEM, Quanta 200FEG, Hillsboro, USA). Python was used to process images from SEM to obtain the volume of pores, and the porosities were the ratio of volume of pores to the corresponding samples. The density was calculated by dividing the mass by the volume.

\section{Results and Discussion}

Figure 1 shows the SEM images of cured samples prepared with different acetone content which were obtained to analyze the porosity and compactness of all samples. The surface of the pure L-PCS was much more porous after curing (Figure 1a), which was mainly attributed to the thermal evaporation of micro-molecules in the PCS during the curing process [26]. With that porosity, inner cracks would be easily generated when external forces are applied, which would further induce the destruction of the whole structure. Besides this, the Energy-dispersive X-ray spectroscopy (EDS) spectrum (Figure 1a) shows that the main elements in pure PCS after curing were $\mathrm{C}$ and $\mathrm{Si}$, and no O element was detected, which was consistent with the results obtained from Figure $1 \mathrm{~h}$. With the increasing of acetone content, less pores and higher compactness of cured samples were detected (Figure 1b,g), which demonstrated that acetone can contribute to the improvement of compactness and carrying capacity. Besides, Figure $2 \mathrm{~h}$ was the EDS spectrum after L-PCS-0 curing, which showed that no other extraneous elements appeared during the curing process (the nitrogen was from the Karstedt's Catalyst).

Figure 2 shows the SEM images of each sample after pyrolyzing. Many through-holes were detected in the fracture surface of the pure PCS sample, and the surface images of pure L-PCS also indicated many pores (Figure 2a). By comparing the fracture morphologies of PCS prepared with different acetone content, which were shown in Figure $2 b-g$, it can be concluded that the pure PCS presented plenty of pores after pyrolyzing, because those pores had already formed during curing and the PCS was already curing during high temperature $\left(>100^{\circ} \mathrm{C}\right)$, which made L-PCS have poor fluidity and filling pores impossible. But, with the increase of acetone content, the fracture porosity of PCS tended to decrease gradually, and the pore diameter and the proportion of through-holes were also reduced at the same time. In addition, about $30 \%$ of the porosities presented in Figures 1 and 2 were open porosities, and the two figures both presented the perfect compactness of samples produced by the optimized impregnation method, which showed its superiority at the same time. What's more, combined with analysis of the EDS spectrum, the main elements in L-PCS-0 after pyrolyzing were $\mathrm{C}$ and $\mathrm{Si}$, and no $\mathrm{O}$ element was detected, as shown in Figure $2 \mathrm{~h}$, which was consistent with the reference [27]. 

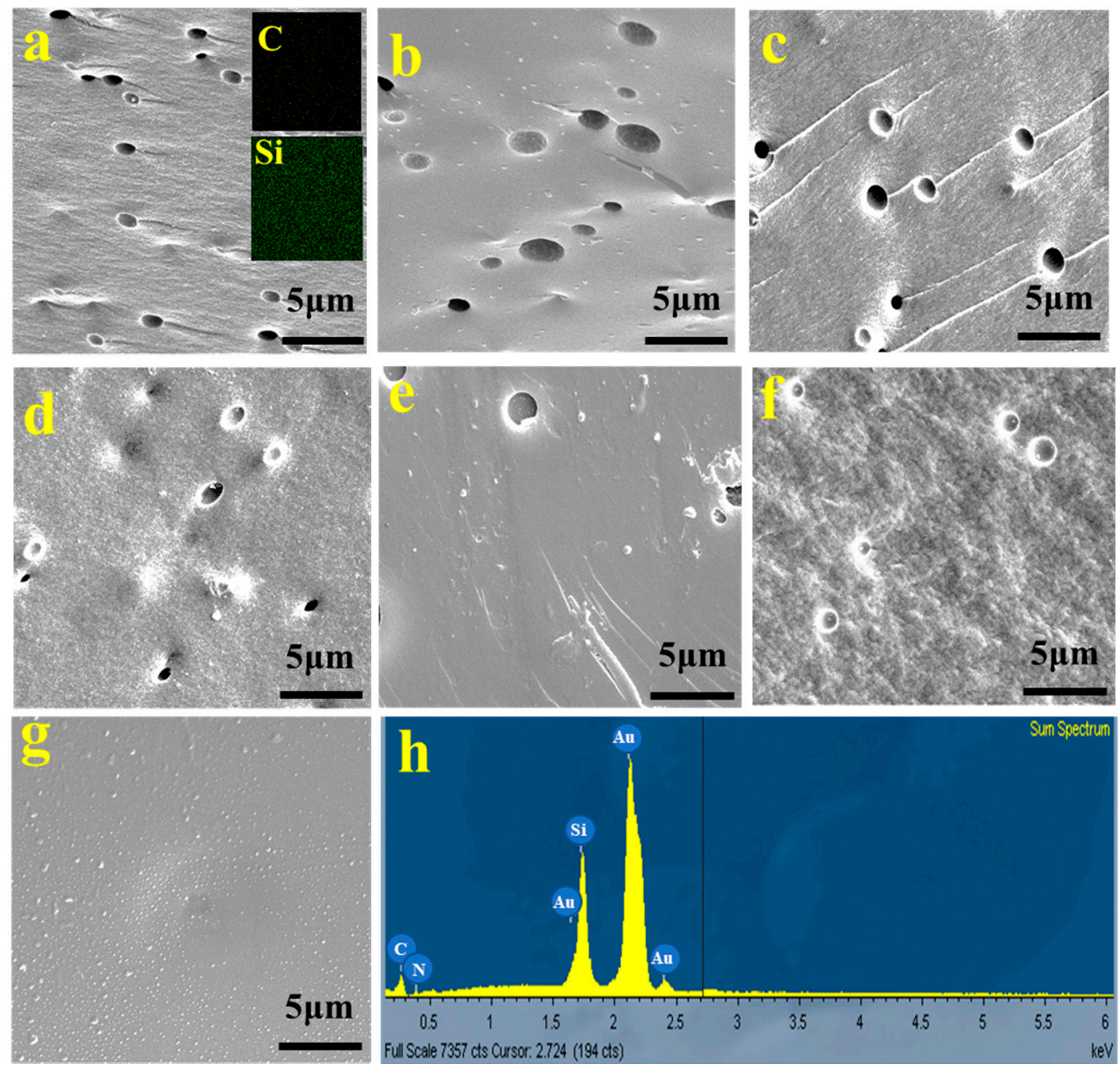

Figure 1. Scanning electron microscopy (SEM) images of all samples prepared with different acetone ratios after curing at $200{ }^{\circ} \mathrm{C}$, and Energy-dispersive X-ray spectroscopy (EDS) energy spectrum after pure polycarbosilane (PCS) curing. (a) without acetone, (b) $1 \mathrm{wt} . \%$, (c) $2 \mathrm{wt} . \%$, (d) $5 \mathrm{wt} . \%$, (e) $10 \mathrm{wt}$ \%, (f) $30 \mathrm{wt.} \%$, (g) $40 \mathrm{wt} . \%$ and (h) EDS energy spectrum of (a).

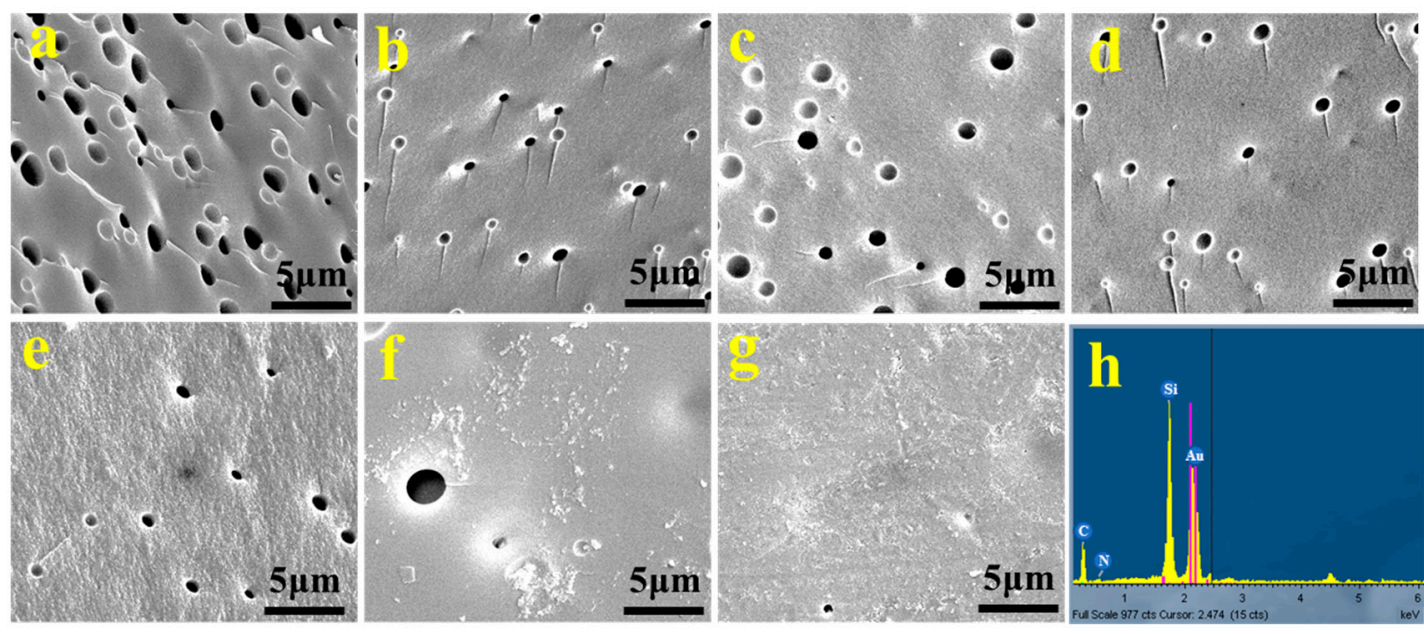

Figure 2. SEM images of all samples prepared with different acetone content after pyrolyzing and EDS energy spectrum after pure PCS pyrolyzing. (a) without acetone, (b) 1 wt.\%, (c) 2 wt.\%, (d) 5 wt.\%, (e) $10 \mathrm{wt.} \%$, (f) $30 \mathrm{wt} . \%$, (g) $40 \mathrm{wt} \%$, and (h) EDS energy spectrum of (a). 
Figure 3 illustrates the influences of acetone content on pore diameter and porosity (which were obtained both by using python to process SEM images). We could see that when the acetone content was relatively high, the pore diameter (shown in the histograms) dropped apparently. However, there were still some exceptions, such as the cured samples after adding $1 \mathrm{wt} . \%$ and $10 \mathrm{wt} . \%$ acetone and the pyrolyzed samples after adding $2 \mathrm{wt} . \%$ and $30 \mathrm{wt} . \%$ acetone, as shown in Figure $3 \mathrm{a}, \mathrm{b}$. It was easy to understand that there were two major factors that affect pore diameters, one was the heating temperature and the other was the number of small molecules. Adding acetone could reduce the number of small molecules effectively (and the mechanism would be explained later), but high temperature during curing and pyrolyzing process generated bubbles in different sizes, and they burst to form pores with different diameters. In addition, the porosities of samples all showed the downward trend (which could be seen from the curves). The results confirm that acetone content does reduce the porosities and improve the compactness to a large extent during both curing and the pyrolyzing process.
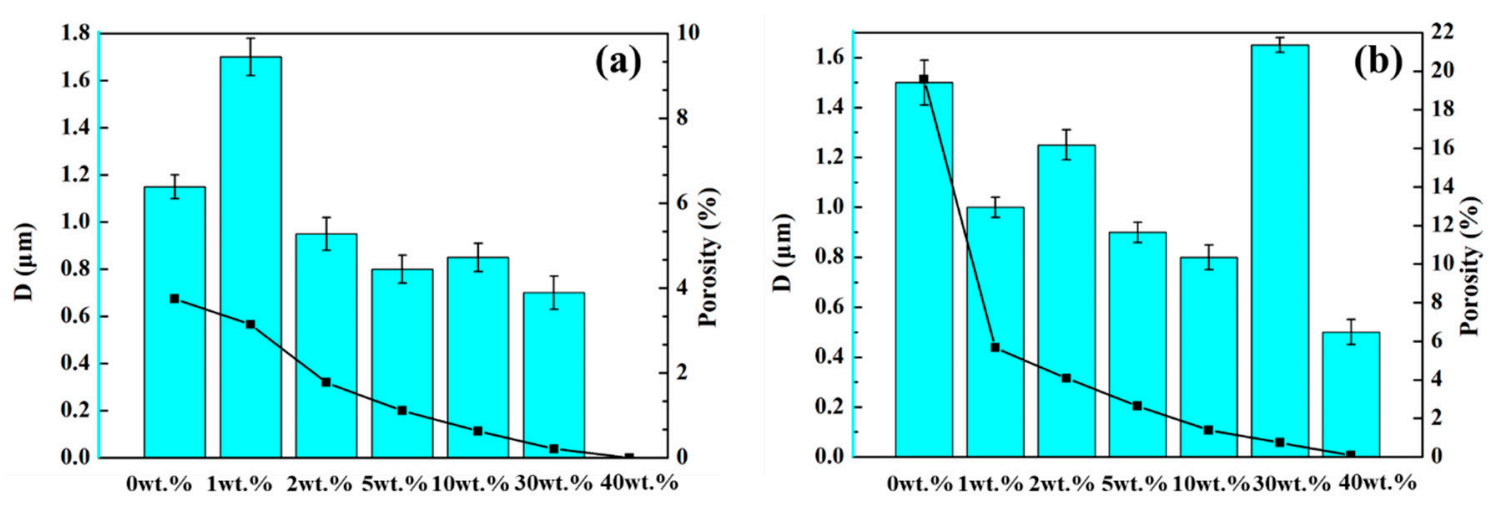

Figure 3. The variation of pore diameter (histograms) and porosities (curves) with different acetone content of all samples after curing and pyrolyzing. (a) Samples after curing and (b) samples after pyrolyzing.

In order to discover the effect of acetone on the impregnation process, viscosities and wetting angles of all samples were tested. The effects of the amount of acetone on the viscosities of L-PCS solutions were presented in Figure 4. The viscosity of L-PCS was greatly reduced with the increase of acetone content under the constant shear rate $80 \mathrm{~s}^{-1}$, and the viscosity of L-PCS with only $1 \mathrm{wt} . \%$ acetone approached $195.5 \mathrm{mPa} \cdot \mathrm{s}$, lower than that of L-PCS solution without acetone $(243.0 \mathrm{mPa} \cdot \mathrm{s}$, consistent with published articles [20,28]). Moreover, the viscosity of L-PCS with $40 \mathrm{wt} . \%$ acetone decreased to $6.0 \mathrm{mpa} \cdot \mathrm{s}$, a factor of about 30 lower than that of L-PCS solution without any acetone. In addition, the viscosities of all samples increased slightly with the increasing shear rate, which could be caused by the "Newtonian behavior" [29,30], as shown in the insert image of Figure 4 .

To verify the acetone introduction's role in the improvement in impregnation efficiency of L-PCS solution, the heating treatment was exploited to decrease the viscosity of L-PCS as a comparison. We heated seven L-PCS samples to specific temperatures and stopped heating once those temperatures were achieved. The heated samples were set to cool naturally at room temperature for $3 \mathrm{~h}$. Another seven samples of L-PCS were added with different acetone content and were placed at room temperature without further processing. The viscosity of heated L-PCS was approximated to $21.6 \mathrm{mPa} \cdot \mathrm{s}$ at $100{ }^{\circ} \mathrm{C}$, which was consistent with the results of published articles [21,22], and the value of viscosity was only equivalent to that with $13 \mathrm{wt} . \%$ acetone addition. However, there was an increase in viscosity of L-PCS with the continuous heat treatment, resulting in an adverse effect in impregnation of L-PCS. Figure 5 shows the viscosity variation of L-PCS under heat treatment and acetone addition after $3 \mathrm{~h}$. The viscosity approached to the minimum value of $220.5 \mathrm{mPa} \cdot \mathrm{s}$ at $30{ }^{\circ} \mathrm{C}$ (with no acetone addition) (Figure 5a), and the viscosity increased sharply with increasing in heat treatment temperature. However, viscosity of L-PCS with only $1 \mathrm{wt} . \%$ acetone introduced was $205.5 \mathrm{mPa} \cdot \mathrm{s}$ (Figure 5b), 
even lower than that of heating treatment at $30^{\circ} \mathrm{C}$, and the viscosity decreased significantly with the increase in acetone content. Therefore, the acetone addition played a significant role in decreasing the viscosity and enhancing the impregnation efficiency of L-PCS precursor and furthermore to decrease both time and economic costs to a great extent.

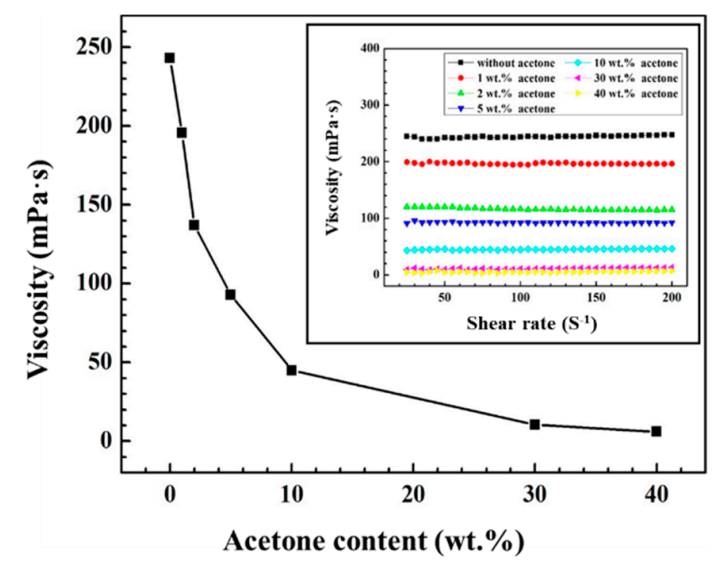

Figure 4. The variation in viscosity with different acetone content of liquid polycarbosilane (L-PCS) solutions.
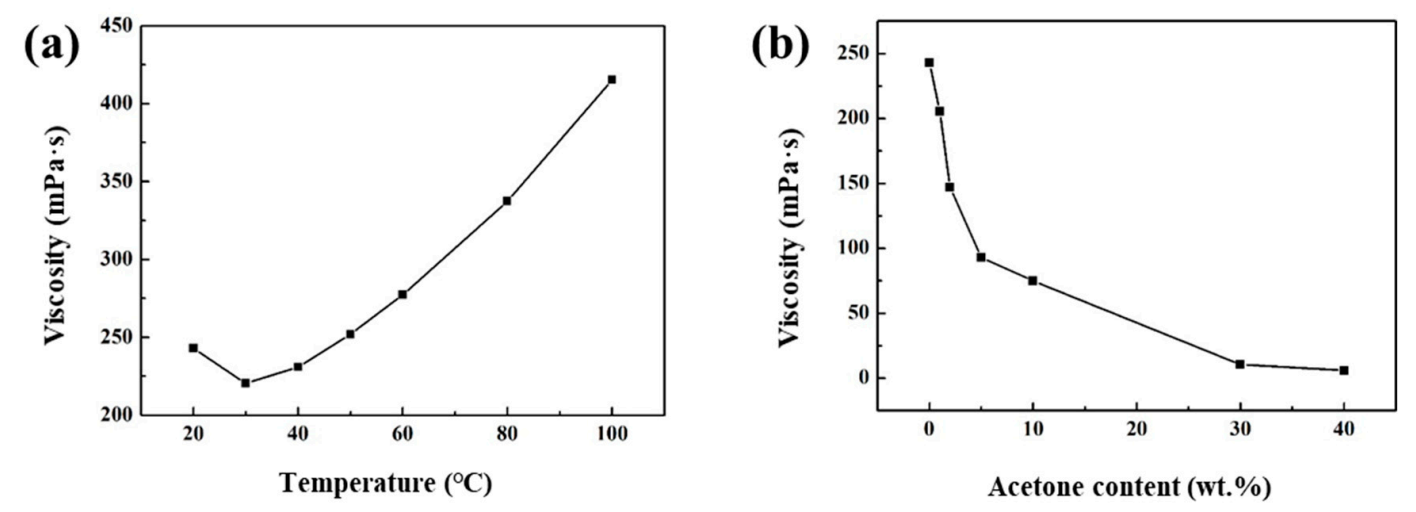

Figure 5. PCS viscosity variation under $80 \mathrm{r} / \mathrm{min}$ rates after $3 \mathrm{~h}$ under (a) heating treatment and (b) acetone introduction.

The wetting angles and surface tension of L-PCS with different acetone content were measured and calculated by wetting angle measuring instrument and capillary lifting [31-33]. The formulas of surface tension $(\sigma)$ and dipping height $(l)$ were as follows [34]:

$$
\begin{gathered}
\sigma=\frac{\rho g h r}{2 \cos \theta} \\
l=\sqrt{\frac{t \sigma d \cos \theta}{4 \mu}}
\end{gathered}
$$

where $\rho$ is the density of the mixed solution, $\theta$ is the wetting angle, $\mu$ is the viscosity of the mixed solution, $r$ is the capillary radius, $t$ is impregnation time, $h$ is the height of the object, and $g$ is the acceleration of gravity, which is equal to $9.8 \mathrm{~m} / \mathrm{s}^{2}$.

The capillary rise height of L-PCS solution was transformed from $12.0 \mathrm{~mm}$ to $16.0 \mathrm{~mm}$ after $40 \mathrm{wt} . \%$ introduction according to the capillary rise method. According to Equation (1), the calculated surface tension of PCS with $40 \mathrm{wt}$.\% acetone was equal to $25.4 \times 10^{-3} \mathrm{~N} / \mathrm{m}$, almost 1.3 times higher than that of pure L-PCS $\left(19.1 \times 10^{-3} \mathrm{~N} / \mathrm{m}\right)$. Moreover, the effects of the amount of acetone on the wetting angles for graphite were presented in Figure 6a. Obviously, it dropped by $37.7 \%$ from $20.2^{\circ}$ for pure 
L-PCS-0 sample to $12.6^{\circ}$ for L-PCS-40 sample. Considering that the diameter of single carbon fiber is about $7 \mu \mathrm{m}$, we set the graphite as the loaner, which had the same chemical property as carbon fibers. The value of wetting angles decreased with the increasing of acetone content, and the dipping height of PCS with $40 \mathrm{wt} . \%$ acetone was $18.9 \mathrm{~mm}$ according to the (Equation (2))-5.9 times higher than that of pure L-PCS $(3.2 \mathrm{~mm})$. The results mentioned above also confirm that acetone has the ability to improve the affinity between fibers and PCS and further to develop their wettability. Furthermore, carbon fibers are chemically stable and have strong corrosion resistance. As a result, acetone will not damage its properties at all. To sum up, the decrease in viscosity and improvement in PCS/graphite wettability were achieved by introducing acetone into L-PCS solutions, leading to an enhancement in impregnation efficiency of L-PCS. The density also presented the descending trend as acetone content increased, as shown in Figure 6b.
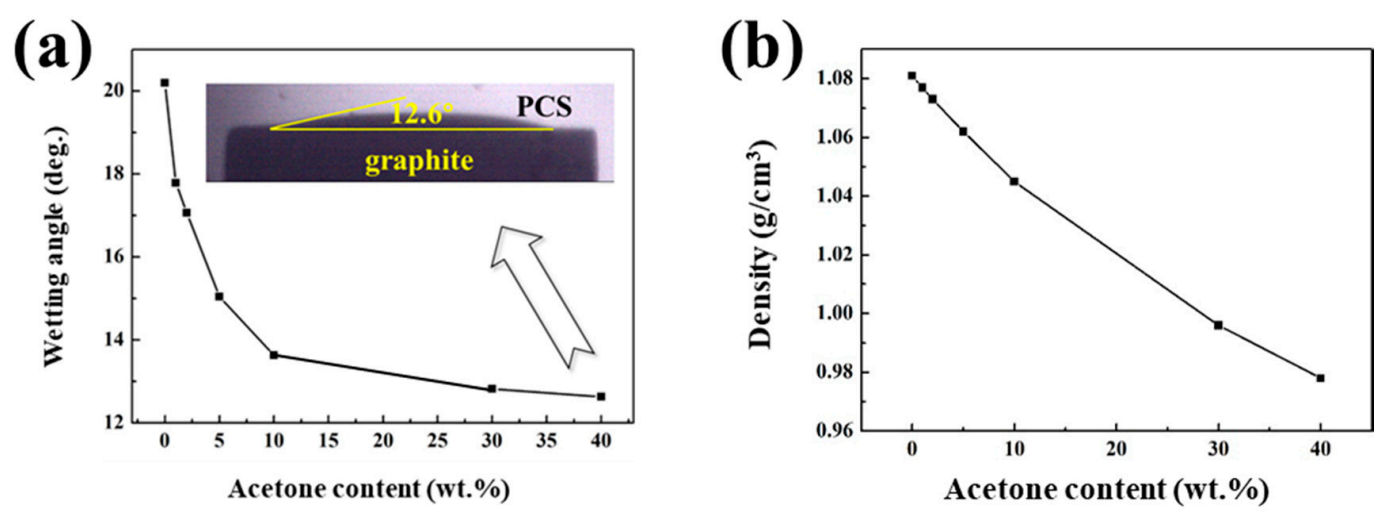

Figure 6. Curve of wetting angles between PCS/graphite and density of all mixtures with different acetone content, (a) wetting angles and (b) density.

To further explore the mechanism of viscosity reduction of L-PCS by adding acetone, GPC, Raman, XRD and FT-IR spectra were acquired. Figure 7 depicts the Raman and FT-IR spectra of L-PCS solutions with different acetone contents. The Si-H $\left(2106 \mathrm{~cm}^{-1}\right)$ and C-H $\left(2897-2978 \mathrm{~cm}^{-1}\right)$ peaks were obviously detected in Figure 7a, indicating that no effect of acetone on the chemical bonds occurred. Moreover, it was known that the introduction of acetone did not change the type and intensity of primary absorption bands except for the new absorption band of $\mathrm{C}=\mathrm{O}\left(1716 \mathrm{~cm}^{-1}\right)$, which existed in acetone (Figure $7 \mathrm{~b}$ ). Therefore, the introduction of acetone did not affect the type of the original chemical bonds, further indicating that acetone did not produce chemical reactions with PCS [35].
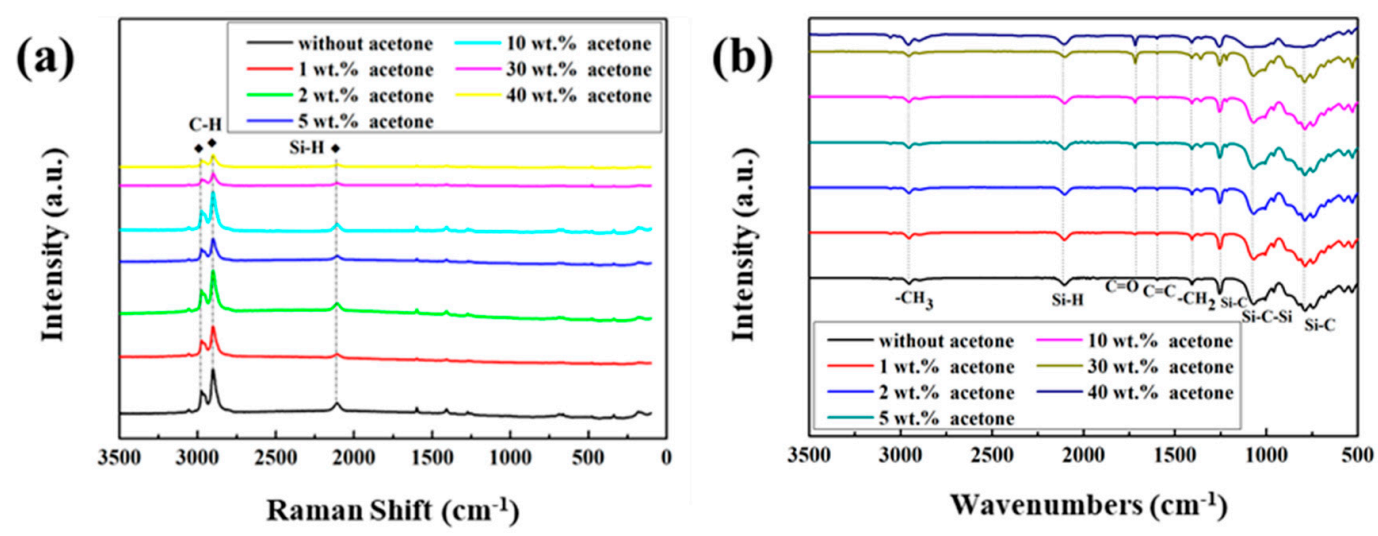

Figure 7. Raman and Fourier transform infrared spectroscopy (FT-IR) spectra of L-PCS solutions with different acetone content. (a) Raman spectra, (b) FT-IR spectra. 
The FT-IR spectra of all cured samples were shown in Figure 8a. The absorption bands of Si-H $\left(2106 \mathrm{~cm}^{-1}\right), \mathrm{C}-\mathrm{H}\left(2897-2978 \mathrm{~cm}^{-1}\right)$, and Si-C $\left(789,1257 \mathrm{~cm}^{-1}\right)$ could be detected. Also, a new absorption band of $\mathrm{C}=\mathrm{O}\left(1716 \mathrm{~cm}^{-1}\right)$ also appeared in pure L-PCS, which was due to the hydration reaction of $C=C$ with water vapor in the air during curing [36]. Besides that, an alcoholic hydroxyl group was formed, which was in turn oxidized by oxygen in high temperature air to introduce a carbonyl group [35,37]. The intensity of the Si-H bond decreased and that of the Si-C bond increased after curing due to the catalytic effect of the curing agent (Figure 8b,c), leading to the cross-linking addition reaction of $\mathrm{C}=\mathrm{C}$ with Si-H [38-40], resulting in an increase in the degree of cross-linking and forming a three-dimensional network structure with Si-C-Si bonds as the skeleton [41,42] (the absorption bands appearing at $496 \mathrm{~cm}^{-1}$ in Figure 8a could be $\mathrm{Si}-\mathrm{O}$, and the acetone added may have absorbed water in the air slightly, which further react with PCS to form a small number of Si-O bonds). The amorphous phase was achieved with different acetone contents, indicating that the curing process was not related to the acetone content (Figure 8d), which was consistent with the results of FT-IR and Raman analysis.
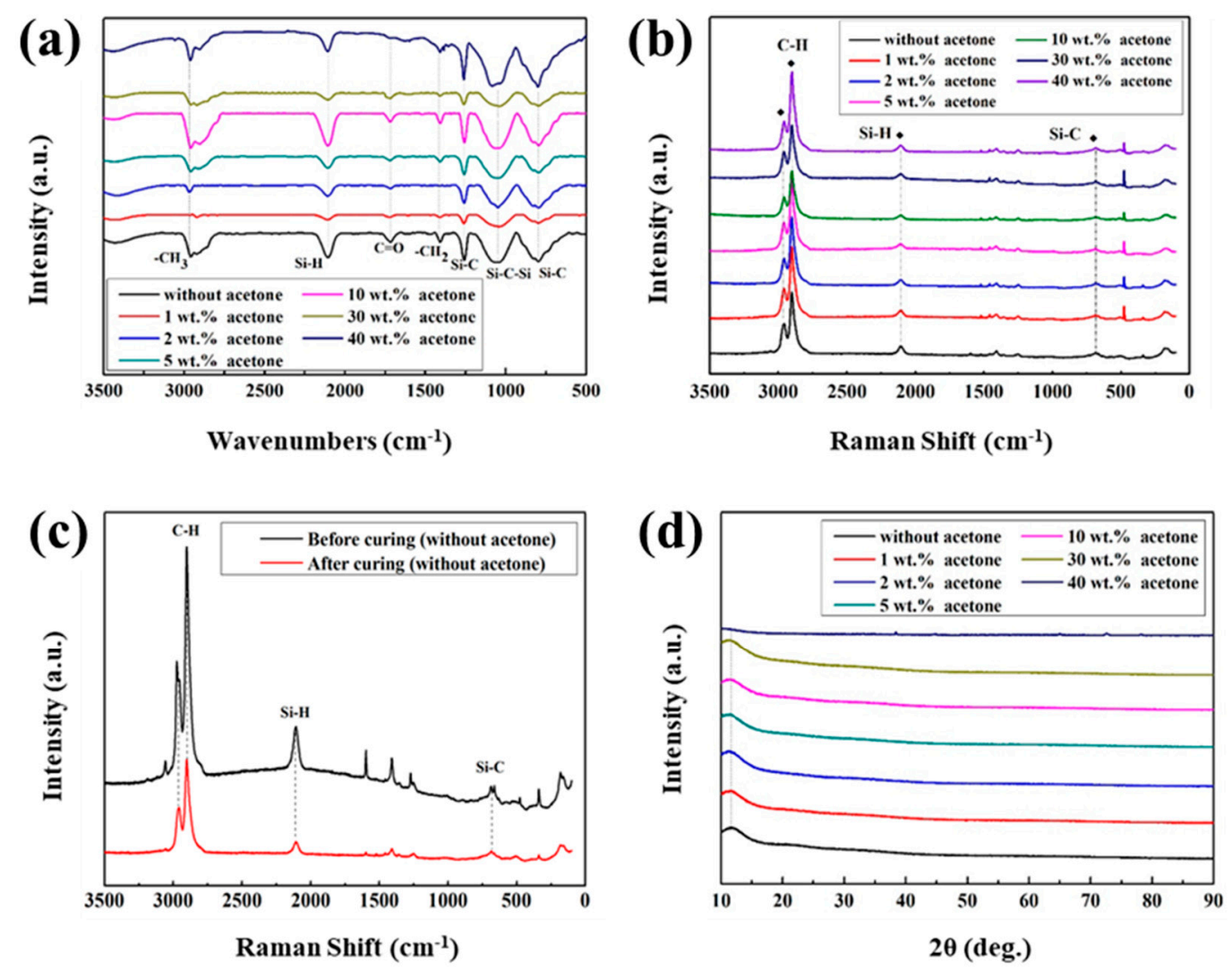

Figure 8. Raman spectra, FT-IR spectra, and X-ray diffraction (XRD) patterns. (a) FT-IR spectra after curing, (b) Raman spectra after curing, (c) Raman patterns before and after curing, and (d) XRD patterns with different acetone contents after curing.

Figure 9 presents the XRD patterns of all samples pyrolyzed at $1300{ }^{\circ} \mathrm{C}$ in the Ar gas environment. There were obvious $\mathrm{SiC}$ diffraction peaks detected in the pyrolyzed PCS samples prepared with different acetone contents. The XRD peaks of crystalline $\mathrm{SiC}$ were broad, indicating that the introduction of acetone did not damage L-PCS properties during the pyrolyzing process. 


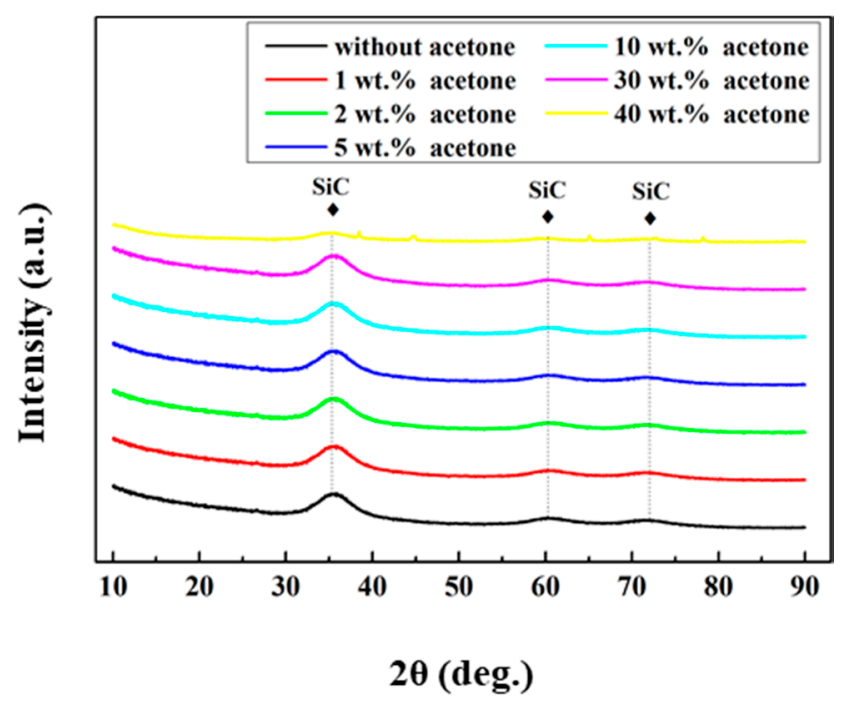

Figure 9. XRD patterns of pyrolyzed PCS prepared with different acetone contents.

Finally, the distribution of PCS molar mass was measured by gel permeation chromatography (GPC), which was shown in Table 1. The molecular weight of PCS fluctuated within a certain range $(\mathrm{Mn}=2100 \pm 50)$ before and after acetone introduction, indicating that acetone introduction did not change the length of PCS chains. The proportion of micro-molecules $(<1500)$ decreased from $27 \%$ to $23 \%$ after $30 \%$ acetone volatilization, resulting in an increase in the number and weight average molecular of L-PCS solution. In addition, the average molecular weight could be the key parameter in dissolving, as seen in Table 1, it was those molecules whose weight were below 1500 that dropped the most. In addition, the curing yield of PCS with $30 \mathrm{wt} . \%$ acetone was measured at $86.6 \%$, lower than that of pure PCS $(90.6 \%)$, which was due to the decrease of the micro-molecules ratio triggered by acetone volatilization [43-45]. Therefore, the decrease of the micro-molecules ratio triggered by acetone volatilization was beneficial for forming a more compact embryo body.

Table 1. Gel permeation chromatography (GPC) test results.

\begin{tabular}{ccccc}
\hline Acetone Introduction & PCS & PCS with 5\% Acetone & PCS with 30\% Acetone & $\begin{array}{c}\text { PCS after 30\% Acetone } \\
\text { Volatilization }\end{array}$ \\
\hline Number average molecular weight & 2093 & 2148 & 2056 & 2297 \\
Weight average molecular weight & 3409 & 3367 & 3301 & 3799 \\
PDI (molecular weight divergence) & 1.63 & 1.57 & 1.6 & 1.65 \\
Molecular weight $>10000$ & $3 \%$ & $3 \%$ & $3 \%$ & $5 \%$ \\
$5000 \sim 10000$ & $17 \%$ & $17 \%$ & $16 \%$ & $19 \%$ \\
$3000 \sim 5000$ & $20 \%$ & $20 \%$ & $21 \%$ & $20 \%$ \\
$1500 \sim 3000$ & $33 \%$ & $34 \%$ & $33 \%$ & $33 \%$ \\
$0 \sim 1500$ & $27 \%$ & $26 \%$ & $28 \%$ & $23 \%$ \\
\hline
\end{tabular}

According to those tests mentioned above, acetone just dissolved micro-molecules of PCS to lower its viscosity, rather than produce chemical reactions with PCS. Additionally, micro-molecules volatilized with acetone during curing, leading to a higher compactness after curing and pyrolyzing, which was consistent with the results of SEM.

\section{Conclusions}

A novel method was proposed to push forward the impregnation process and reduce both time and economic costs via acetone introduction. In this way, the compactness was highly improved and the period and costs of production were decreased by reducing viscosity and improving impregnation efficiency. The viscosity was $6.0 \mathrm{mPa} \cdot \mathrm{s}$ with $40 \mathrm{wt} . \%$ acetone added, approximately a factor of 30 lower than that of original polycarbosilane, and the viscosity of PCS remained at a low level in the several 
hours after acetone introduction. Furthermore, no chemical reaction was produced between acetone and PCS. Acetone just dissolved the micro-molecules in PCS and brought them out when acetone volatilized, which greatly improved the compactness of $\mathrm{C} / \mathrm{SiC}$ composites. The optimum additive quantity of acetone from this paper is between $30 \mathrm{wt} . \%$ and $40 \mathrm{wt} . \%$, as the effect of lower content was not obvious, while higher content would make it hard to pre-remove the acetone content before curing and pyrolyzing. Furthermore, Figure 4 may serve as a reference for different specific situations. All the results mentioned above provide guidance for efficient and economical impregnation and preparation.

Author Contributions: Conceptualization, Y.L; methodology, Y.L.; data curation, P.H. and X.L.; writing-original draft preparation, X.L.; writing-review and editing, X.L.; project administration, Y.L. and P.H. All authors have read and agreed to the published version of the manuscript.

Funding: The authors thank the National Natural Science Foundation of China (11602073) and the Natural Science Foundation of Heilongjiang Province of China (QC2018005), and the research is also supported by "the Fundamental Research Funds for the Central Universities" (Grant No.HIT.NSRIF.201821) and the State Scholarship Fund (201706125076) from China Scholarship Council.

Conflicts of Interest: The authors declare no conflict of interest.

\section{References}

1. Fan, S.W.; Sun, H.D.; Ma, X.; Deng, J.L.; Yang, C.; Cheng, L.F.; Zhang, L.T. Microstructure and properties of a new structure-function integrated C/C-SiC brake material. J. Alloys Comp. 2018, 769, 239-249. [CrossRef]

2. Cai, Y.Z.; Cheng, L.F.; Zhang, H.J.; Yin, X.W.; Yin, H.F.; Yan, G.Z. Effects of graphite fillers on the thermophysical properties of 3D C/SiC composites. J. Alloys Comp. 2019, 770, 989-994. [CrossRef]

3. Omrani, E.; Barari, B.; Moghadam, A.D.; Rohatgi, P.K.; Pillai, K.M. Mechanical and tribo-logical properties of self-lubricating bio-based carbon fabric epoxy composites made using liquid composite molding. Tribol. Int. 2015, 92, 222-232. [CrossRef]

4. Fan, S.W.; Zhang, L.T.; Cheng, L.F.; Tian, G.L.; Yang, S.J. Effect of braking pressure and braking speed on the tribological properties of C/SiC aircraft brake materials. Compos. Sci. Technol. 2010, 70, 959-965. [CrossRef]

5. Lv, X.Y.; Ye, F.; Cheng, L.F.; Fan, S.W.; Liu, Y.S. Fabrication of SiC whisker-reinforced SiC ceramic matrix composites based on 3D printing and chemical vapor infiltration technology. J. Eur. Ceram. Soc. 2019, 39, 3380-3386. [CrossRef]

6. Hu, P.; Zhang, D.Y.; Dong, S.; Qiang, Q.; Zhang, X.H. A novel vibration-assisted slurry impregnation to fabricate $\mathrm{C}_{\mathrm{f}} / \mathrm{ZrB}_{2}-\mathrm{SiC}$ composite with enhanced mechanical properties. J. Eur. Ceram. Soc. 2019, 39, $798-805$. [CrossRef]

7. Baker, B.; Rubio, V.; Ramanujam, P.; Binner, J.; Hussain, A.; Ackerman, T.; Brown, P.; Dautremont, I. Development of a slurry injection technique for continuous fiber ultra-high temperature ceramic matrix composites. J. Eur. Ceram. Soc. 2019, 39, 3927-3937. [CrossRef]

8. Zhang, B.; Huang, H.; Lu, X. Fabrication and properties of $\mathrm{C}_{\mathrm{f}} / \mathrm{SiC}$ porous ceramics by grinding-mould pressing-sintering process. J. Eur. Ceram. Soc. 2019, 39, 1775-1780. [CrossRef]

9. Hu, C.L.; Tang, S.F.; Pang, S.Y.; Cheng, H.M. Long-term oxidation behaviors of C/SiC composites with a $\mathrm{SiC} / \mathrm{UHTC} / \mathrm{SiC}$ three-layer coating in a wide temperature range. Corros. Sci. 2019, 147, 1-8. [CrossRef]

10. Ma, X.K.; Yin, X.W.; Fan, X.M.; Cao, X.Y.; Yang, L.W.; Sun, X.N.; Cheng, L.F. Improved tensile strength and toughness of dense $C_{f} / S i C-S i B C$ with tailored PyC interphase. J. Eur. Ceram. Soc. 2019, 39, 1766-1774. [CrossRef]

11. Vinci, A.; Zoli, L.; Sciti, D. Influence of fiber content on the strength of carbon fiber reinforced $\mathrm{H}_{\mathrm{f}} \mathrm{C}_{\mathrm{f}} / \mathrm{SiC}$ composites up to $2100{ }^{\circ}$ C. J. Eur. Ceram. Soc. 2019, 39, 3594-3603. [CrossRef]

12. Kashyap, S.K.; Mitra, R. Effect of $\mathrm{LaB}_{6}$ additions on densification, microstructure, and creep with oxide scale formation in $\mathrm{ZrB}_{2}$-SiC composites sintered by spark plasma sintering. J. Eur. Ceram. Soc. 2019, 39, 2782-2793. [CrossRef]

13. Zhang, D.Y.; Hu, P.; Dong, S.; Liu, X.; Wang, C.L.; Nan, Z.Z.; Zhang, X.H. Oxidation behavior and ablation mechanism of $\mathrm{C}_{\mathrm{f}} / \mathrm{ZrB}_{2}$-SiC composite fabricated by vibration-assisted slurry impregnation combined with low-temperature hot pressing. Corros. Sci. 2019, 161, 108181. [CrossRef] 
14. Rubio, V.; Binner, J.; Cousinet, S.; Page, G.L.; Ackerman, T.; Hussain, A.; Brown, P.; Dautremont, I. Materials characterization and mechanical properties of $\mathrm{C}_{\mathrm{f}}$-UHTC powder composites. J. Eur. Ceram. Soc. 2019, 39, 813-824. [CrossRef]

15. Yan, C.L.; Liu, R.J.; Cao, Y.B.; Zhang, C.R. Fabrication and properties of PIP 3D C $\mathrm{f} / \mathrm{ZrC}-\mathrm{SiC}$ composites. Mater. Sci. Eng. A 2014, 591, 105-110. [CrossRef]

16. Hu, Y.; Luo, F.; Duan, S.C.; Zhou, W.C.; Zhu, D.M. Mechanical and dielectric properties of $\mathrm{SiC}_{\mathrm{f}} / \mathrm{SiC}$ composites fabricated by PIP combined with CIP process. Ceram. Int. 2016, 42, 6800-6806. [CrossRef]

17. Garcia, B.W. Preceramic Resin Formulations, Ceramic Materials Comprising the Preceramic Resin Formulations, and Related Articles and Methods. U.S. Patent Application No. 10,731,036, 4 August 2020.

18. Xiong, H.W.; Chen, H.H.; Zhao, L.Z.; Huang, Y.J.; Zhou, K.C.; Zhang, D. SiCw/SiCp reinforced 3D-SiC ceramics using direct ink writing of polycarbosilane-based solution: Microstructure, composition and mechanical properties. J. Eur. Ceram. Soc. 2019, 39, 2648-2657. [CrossRef]

19. He, J.B.; Gao, Y.; Wang, Y.G.; Fang, J.Y.; An, L.N. Synthesis of $\mathrm{ZrB}_{2}-\mathrm{SiC}$ nanocomposite powder via polymeric precursor route. Ceram. Int. 2017, 43, 1602-1607. [CrossRef]

20. Zheng, G.B.; Sano, H.; Uchiyama, Y.; Kobayashi, K.; Cheng, H.M. Effect of boron addition on oxidation resistance of carbon fiber polycarbosilane-derived SiC composites. J. Mater. Sci. Lett. 1998, 17, 2047-2049. [CrossRef]

21. Jian, K.; Chen, Z.H.; Ma, Q.S.; Hu, H.F.; Zheng, W.W. Effects of polycarbosilane infiltration processes on the microstructure and mechanical properties of 3D- $\mathrm{C}_{\mathrm{f}} / \mathrm{SiC}$ composites. Ceram. Int. 2007, 33, 905-909. [CrossRef]

22. Bae, J.C.; Cho, K.Y.; Yoon, D.H.; Baek, S.S.; Park, J.K.; Kim, J.L.; Im, D.W.; Riu, D.H. Highly efficient densification of carbon fiber-reinforced $\mathrm{SiC}$-matrix composites by melting infiltration and pyrolysis using polycarbosilane. Ceram. Int. 2013, 39, 5623-5629. [CrossRef]

23. Gupta, R.K.; Mishra, R.; Tiwari, R.K.; Ranjan, A.; Saxena, A.K. Studies on the rheological behavior of polycarbosilane part I: Effect of time, temperature and atmosphere. Silicon 2011, 3, 27-35. [CrossRef]

24. Tian, Q.; Wu, N.; Wang, B.; Wang, Y.D. Fabrication of hollow SiC ultrafine fibers by single-nozzle electrospinning for high-temperature thermal insulation application. Mater. Lett. 2019, 239, 109-112. [CrossRef]

25. Zhou, H.J.; Yang, J.S.; Le, G.; Ni, D.W.; Wang, H.D.; Dong, S.M. Effect of ZrC amount and distribution on the thermomechanical properties of $\mathrm{C}_{\mathrm{f}} / \mathrm{SiC}-\mathrm{ZrC}$ composites. Int. J. Appl. Ceram. Technol. 2019, 16, 1321-1328. [CrossRef]

26. Usevičiūtè, L.; Baltrènaitè, E. Methods for determining lignocellulosic biochar wettability. Waste Biomass Valorization 2019, 11, 4457-4468. [CrossRef]

27. Bouillon, E.; Langlais, F.; Pailler, R.; Naslain, R.; Cruege, F.; Huong, P.V.; Sarthou, J.C.; Delpuech, A.; Laffon, C.; Lagarde, P. Conversion mechanisms of a polycarbosilane precursor into a SiC-based ceramic material. J. Mater. Sci. 1991, 26, 1333-1345. [CrossRef]

28. Fang, Y.H.; Huang, M.H.; Yu, Z.J.; Xia, H.P.; Chen, L.F.; Zhang, Y.; Zhang, L.T. Synthesis, characterization, and pyrolytic conversion of a novel liquid polycarbosilane. J. Am. Ceram. Soc. 2008, 91, 3298-3302. [CrossRef]

29. Rajinder, P. Shear viscosity behavior of emulsions of two immiscible liquids. J. Colloid Interface Sci. 2000, 225, 359-366.

30. Eshgarf, H.; Afrand, M. An experimental study on rheological behavior of non-Newtonian hybrid nano-coolant for application in cooling and heating systems. Exp. Therm. Fluid Sci. 2016, 76, 221-227. [CrossRef]

31. Sterczyńska, A.; Śliwińska-Bartkowiak, M.; Zienkiewicz-Strzałka, M.; Derylo-Marczewska, A. Surface properties of synthesized nanoporous carbon and silica matrices. J. Vis. Exp. 2019, 145. [CrossRef]

32. Wang, K.; Ding, C.N.; Jiang, S.G.; Wu, Z.Y.; Shao, H.; Zhang, W.Q. Application of the addition of ionic liquids using a complex wetting agent to enhance dust control efficiency during coal mining. Process. Saf. Environ. Prot. 2019, 122, 13-22. [CrossRef]

33. Zhao, G.J.; Yuan, Z.M.; Yin, J.G.; Ma, S.X. Thermophysical properties of fatty acid methyl and ethyl esters. J. Chem. Thermodyn. 2019, 134, 195-212. [CrossRef]

34. Kim, K.R.; Choi, S.Y.; Kim, J.G.; Paek, S.; Goh, W.I. Electrochemical investigation of exchange current density of uranium and rare-earths couples $\left(\mathrm{M}_{3} / \mathrm{M}_{0}\right)$ in LiCl- $\mathrm{KCl}$ eutectic electrolyte. Int. J. Electrochem. Sci. 2015, 10, 7660-7670. 
35. Ye, X.L.; Chen, Z.F.; Ai, S.F.; Hou, B.; Zhang, J.X.; Zhou, Q.B.; Liu, H.Z.; Cui, S. Effect of thickness of SiC films on compression and thermal properties of $\mathrm{SiC} / \mathrm{C}_{\mathrm{f}}$ Composites. Ceram. Int. 2019, 45, 4674-4679. [CrossRef]

36. Li, L.; Barnett, K.J.; McClelland, D.J.; Zhao, D.T.; Liu, G.Z.; Huber, G.W. Gas-phase dehydration of tetrahydrofurfuryl alcohol to dihydropyran over $\Upsilon-\mathrm{Al}_{2} \mathrm{O}_{3}$. Appl. Catal. B 2019, 245, 62-70. [CrossRef]

37. Zhang, Z.W.; Fang, L.; Xiang, H.C.; Xu, M.Y.; Tang, Y.; Jantunen, H.L.; Li, C.C. Structural, infrared reflectivity spectra and microwave dielectric properties of the $\mathrm{Li}_{7} \mathrm{Ti}_{3} \mathrm{O}_{9} \mathrm{~F}$ ceramic. Ceram. Int. 2019, 45, 10163-10169. [CrossRef]

38. Lu, Z.Z.; Cao, J.W.; Bai, S.Z.; Wang, M.Y.; Li, D.C. Microstructure and mechanical properties of TiAl-based composites prepared by stereolithography and gel casting technologies. J. Alloys Compd. 2015, 633, 280-287. [CrossRef]

39. Ashby, B.A. Addition reaction. U.S.S.R. 1964, 662, 159.

40. Sangermano, M.; Marchi, S.; Meier, P.; Kornmann, X. UV-activated hydrosilation reaction for silicone polymer crosslinking. J. Appl. Polym. Sci. 2013, 128, 1521-1526. [CrossRef]

41. Tang, X.Y.; Zhang, L.; Tu, H.B.; Gu, H.; Chen, L.F. Decarbonization mechanisms of polycarbosilane during pyrolysis in hydrogen for preparation of silicon carbide fibers. J. Mater. Sci. 2010, 45, 5749-5755. [CrossRef]

42. Li, H.B.; Zhang, L.T.; Cheng, L.F.; Wang, Y.G.; Yu, Z.J.; Huang, M.H.; Tu, H.B.; Xia, H.P. Polymer-ceramic conversion of a highly branched liquid polycarbosilane for SiC-based ceramics. J. Mater. Sci. 2008, 43, 2806-2811. [CrossRef]

43. Guo, W.J.; Bai, S.X.; Ye, Y.C.; Zhu, L.; Li, S. C/C-SiC composite fabricated via PCS-Si slurry reactive melt infiltration. Int. J. Appl. Ceram. Technol. 2019, 16, 88-96. [CrossRef]

44. Hoffman, R.L. Explanations for the cause of shear thickening in concentrated colloidal suspensions. J. Rheol. 1998, 42, 111-123. [CrossRef]

45. Hurwitz, F.I. Filler/Polycarbosilane Systems as CMC Matrix Precursors; The American Ceramic Society: Westerville, OH, USA, 1998.

Publisher's Note: MDPI stays neutral with regard to jurisdictional claims in published maps and institutional affiliations.

(C) 2020 by the authors. Licensee MDPI, Basel, Switzerland. This article is an open access article distributed under the terms and conditions of the Creative Commons Attribution (CC BY) license (http://creativecommons.org/licenses/by/4.0/). 